\title{
Poe, Baudelaire, e a estética romântica do fragmento ${ }^{1}$
}

Renata Philippov - Unifesp

Para Edgar Allan Poe, a questão formal é de suprema importância. Enquanto a ampla maioria dos românticos ingleses (paradigma literário ainda em voga em um país recentemente independente, caso dos Estados Unidos) dão livre curso à imaginação criadora e à subjetividade, enquanto contemporâneos e conterrâneos de Poe voltam-se para o panteísmo transcendentalista, Poe prefere direcionar suas obras controlando a imaginação criadora com primazia da forma e com o emprego da razão. Assim, tanto seus primeiros poemas, quanto os contos e ensaios críticos chamam a atenção para o fato de que sempre deveria predominar uma unidade de sentido e de efeito racionalmente controladas e antecipadamente planejadas, com emprego de artifícios retóricos tributários da estética clássica. Para tal, segundo o próprio autor, como afirma em ensaios como "Philosophy of Composition" [Filosofia da Composição], "Poetic Principle" [Princípio

\footnotetext{
${ }^{1}$ Este artigo origina-se, em parte, de tese de doutoramento inédita, defendida em 2005 na Universidade de São Paulo.
} 
Poético], "The Rationale of Verse" [O Princípio do Verso] ${ }^{2}$, além de na resenha dedicada à obra de Nathaniel Hawthorne, "Review of Twice-Told Tales" [Nathaniel Hawthorne] ${ }^{3}$, todos os acontecimentos narrados, todas as imagens e metáforas, o campo lexical utilizado, a temática escolhida, enfim, todos os elementos constitutivos da prosa e poesia deveriam ser cuidadosamente criados visando a um efeito final. Portanto, nada que não fosse extremamente relevante poderia aparecer no texto, dando-lhe assim unidade de sentido e amarramento retórico.

Assim é o caso de sua produção poética e narrativa, embora já na época de maturidade estética e poética e no final de sua vida, na década de 1840, ao compor Eureka (1848), poema em prosa também chamado pelo autor de tratado de cosmogonia, tal primazia da unidade de efeito via rigidez formal tenha começado a se desintegrar. Eureka discute longamente a formação do universo a partir de uma explosão inicial, ou seja, a criação do universo teria sido iniciada por uma explosão atômica, originando moléculas infinitas que se reagrupariam formando novos átomos, novos corpos estelares em escala. Segundo Poe, o universo estaria em constante expansão atômica, fruto de tal explosão inicial, pela qual os átomos se reagrupariam pelo processo de atração e repulsão. No entanto, Poe alerta para o futuro do cosmos: após infinitos rearranjos das partículas, haveria, um dia, o processo oposto, ou seja, o da tentativa de voltar à unidade pré-explosão. Assim, os infinitos fragmentos tenderiam a voltar ao estágio inicial, em processo de volta à totalidade que acarretaria destruição atômica. O universo, portanto, estaria fadado ao desaparecimento, à aniquilação total e irremediável.

\footnotetext{
${ }^{2}$ Ensaio sem tradução para o português.

3 Vide a tradução de Sarmento de Beires (1950)..
} 
Até hoje pouco estudado pela crítica ${ }^{4}$, Eureka não recebeu elogios quando de sua publicação. Poe, no entanto, ao término da elaboração desse texto, por ele chamado de poema em prosa, iria considerá-lo o ponto máximo de sua poética e sentir-se incapaz de quaisquer outras obras. Assim, o autor tomou tal poema em prosa como resumo de toda sua teoria estética e produção poética, como ponto máximo de sua imaginação criadora. De fato, tratou Eureka como um sonho, dedicando-o "aos sonhadores e àqueles que põem fé em sonhos como as únicas realidades". (Poe, 1848, p. 5)

Assim, pode-se considerar Eureka como um poema em prosa metalinguístico: em vez de mero tratado cosmogônico, temos um discurso sobre o ato de criar. Assim como o universo teria sido originado a partir de uma totalidade, a produção literária surge a partir do autor. Suas ideias se expandem pelo cosmos, ou seja, em meio ao público leitor. O movimento de volta ao uno, no entanto, desencadeia aniquilação. Uma vez criada, a obra não mais pode retornar a sua origem. O mais importante, porém, para este trabalho aqui se refere à visão da fragmentação como parte inerente à criação poética. Em Eureka, o universo se divide em fragmentos sucessivos que se reagrupam de acordo com a necessidade. O retorno do múltiplo rumo ao uno, entretanto, está fadado à destruição.

Vale salientar que, embora Poe tenha efetivamente dado importância à unidade de sentido, ao uno, ao indivisível, ao controle total sobre os elementos ou fragmentos, percebe, no auge de sua maturidade crítica e poética, a utopia de tal controle. O que os primeiros românticos alemães, como Novalis e Friedrich Schlegel, mostraram em seus fragmentos estéticos, Poe preferiu

\footnotetext{
${ }^{4}$ À exceção de estudos como os de Van Slooten (2011).
} 
mostrar em nova forma: o poema em prosa. Assim, a própria escolha formal remete à temática da fragmentação discutida em Eureka. O poema em prosa enquanto forma implica mistura híbrida de gêneros: a musicalidade e imagética próprias do poema e a liberdade da narrativa. Entretanto, ainda assim temos um controle formal, em menor escala do que nos outros escritos do poeta, é verdade: com começo, meio e fim, coesão e coerência textuais, o poema em prosa ainda mantém sobre si controle racional. No entanto, temos um controle formal aliado à temática da destruição, da fragmentação inexorável, fenômeno antecipado em alguns poemas de juventude, como "The Haunted Palace" [O Palácio Assombrado], "Conqueror Worm" [O Verme Triunfante] e "The Coliseum" [O Coliseu $]^{5}$, poemas cuja temática também remete à aniquilação final, mas cuja forma apresenta sólido controle da forma.

Ao analisarmos diacronicamente a obra de Poe, podemos afirmar que a busca de rigidez formal perpassa a grande maioria de seus escritos. Uma grande exceção pode ser vista em A Chapter of Suggestions, Fifty Suggestions, Marginalia e Marginal Notes ${ }^{6}$ [Um Capítulo de Sugestões, Cinquenta Sugestões, Marginália e Notas Marginais], conjuntos de textos publicados mensalmente em periódicos e jornais onde trabalhou e para os quais contribuiu, entre 1844 e 1849, fase final de sua produção. Neles, Poe se dedicou a tecer análises críticas acerca de vários escritores contemporâneos, bem como a reiterar seus critérios estéticos e poéticos.

Em A Chapter of Suggestions, conjunto de fragmentos de texto, pensamentos ou aforismos sem relação coesa, parágrafo

\footnotetext{
${ }^{5}$ Vide a tradução de Margarida Vale de Gato (2009).

${ }^{6}$ Obras inéditas em português. As traduções dos títulos são minhas.
} 
a parágrafo, e publicados em 1845 em The Opal, além de tecer comentários críticos e irônicos sobre a sociedade de seu tempo e escritores contemporâneos, analisa brevemente três questões fundamentais para se entender a estética de seu autor: o efeito final na narrativa, a imaginação e a musicalidade. Embora tenha aprofundado o conteúdo de tais fragmentos em ensaios de fôlego como "The Poetic Principle" [Princípio Poético] e "The Philosophy of Composition" [Filosofia da Composição], aqui lança, com verdadeira precisão cirúrgica, comentários sobre tais questões. Vejamos dois exemplos dentre os vários fragmentos. Com relação à imaginação, define-a enquanto instância captadora dos segredos etéreos e sobrenaturais:

Que a imaginação não tenha sido injustamente classificada como suprema dentre as faculdades mentais, parece a partir de uma consciência intensa, por parte do homem de imaginação, que a faculdade em questão leva frequentemente sua alma a vislumbrar rapidamente coisas supremas e eternas - a ponto de quase alcançar os grandes segredos. Há momentos, de fato, nos quais percebe os tênues perfumes, e escuta as melodias de um mundo mais feliz. Alguns dos mais profundos conhecimentos - talvez todos os mais profundos conhecimentos - originaram-se de uma imaginação muito estimulada. Grandes intelectos adivinham bem. As leis de Kepler foram, confessadamente, adivinhações. (Poe, 1984, p. 1293. Ênfase no original.)

Com relação à importância da música para a poesia, presente igualmente em muitos de seus poemas, como "The Raven" 
[O Corvo], "The Bells" [Os Sinos] e "Annabel Lee", o autor nos diz:

A grande variedade de expressão melodiosa que é transmitida pela teclas de um piano pode ser transformada, em mãos adequadas, na base de um excelente conto de fadas. Deixe o poeta pressionar constantemente seus dedos em cada tecla, mantendo-a apertada, e imagine que cada série prolongada de ondulações traz a história, de alegria ou pesar, contada por um espírito bom ou maligno aprisionado dentro dele". (Poe, 1984, p. 1295)

Fifty Suggestions, como o título já anuncia, consiste em cinquenta pequenas sugestões ou fragmentos numerados pelo autor e publicados em maio e junho de 1849 na Graham's Magazine. Dentre os diversos fragmentos acerca de escritores e editores contemporâneos, críticas sarcásticas e irônicas contra a mentalidade de seu tempo, Poe, assim como em A Chapter of Suggestions, também menciona aspectos de sua teoria estética como o papel do gosto, o gênio incompreendido e o caráter cíclico do pensamento. A sugestão ou fragmento 26, por exemplo, ironicamente critica os Transcendentalistas, seus contemporâneos:

O gosto manifestado por nossos poetas transcendentalistas deve ser tratado 'com reverência', sem dúvida alguma, como um dos amigos do Sr. Emerson sugere - pois o fato é que se trata de Gosto em seu leito de morte - Gosto chutando in articulo mortis. (Poe, 1984, p. 1303. Ênfase dada pelo autor no original.) 
Mas é Marginalia o conjunto de fragmentos mais estudados pela crítica e relevantes para nós aqui. Trata-se de um conjunto de vinte e sete partes de texto, algumas mais desenvolvidas e prontas para serem publicadas, posto que sob forma de ensaios curtos, outras apenas em formato de notas esparsas lançadas em periódicos norte-americanos entre 1844 e 1849, como US Magazine and Democratic Review, Godey's Lady's Book, Broadway Journal, Graham's Magazine, Democratic Review e Southern Literary Messenger, que ele editou e para os quais contribuiu intensamente, em carreira jornalística paralela à de poeta e contista.

O termo marginalia, cuja origem remonta ao Latim vulgar como plural de marginalis, significa aquilo que foi escrito à margem de um texto, anotações críticas, objetivas e subjetivas acerca do que está impresso. O próprio Poe justifica a escolha do nome em um dos primeiros fragmentos, publicado em novembro de 1844 na Democratic Review:

Ao obter meus livros, sempre quis uma margem ampla; não pelo fato exclusivamente de amar a coisa em si, apesar de ser agradável, mas sim pela facilidade que me proporciona em poder rabiscar pensamentos sugeridos, concordâncias e diferenças de opinião ou breves comentários críticos em geral. Onde o que tenho a dizer é demais para caber dentro dos limites estreitos da margem, anoto-o em um pedaço de papel e o deposito entre as folhas; tomo cuidado para prendê-lo com uma porção imperceptível de goma adragante [...] Os marginalia são deliberadamente rabiscados, pois a mente do leitor deseja se livrar de um pensamento, - 
independentemente de ser irreverente, bobo ou trivial - ainda sim um pensamento, não meramente algo que possa ter sido um dia, e sob circunstâncias mais favoráveis, um pensamento. Nos marginalia, também, falamos apenas para nós mesmos; portanto, falamos com frescor, ousadia, originalidade e abandono, sem presunção [...]. (Poe, 1984, p. 1309).

Mais adiante no mesmo fragmento, descreve como transformar anotações desconexas e pessoais em textos inteligíveis e passíveis de publicação, o que realmente fez de 1844 a 1849:

Deve haver algo mesmo em minhas anotações que, dado o próprio caráter de anotações, possa interessar aos outros.

A maior dificuldade teve a ver com o modo de transferência de anotações para os volumes - o contexto do texto - levando em conta o tecido de compreensibilidade profundamente frágil no qual o contexto estava inserido [...]

Decidi, no final, depositar bastante fé na sagacidade e imaginação do leitor: essa é a regra geral. Mas, em alguns momentos, onde nem mesmo a fé poderia remover montanhas, não parecia haver plano mais seguro do que ajustar a nota para, pelo menos, transmitir o fantasma de uma concepção sobre aquilo de que se tratava afinal [...]. (Poe, 1984, p. 1310 - 1311).

Portanto, o próprio autor demonstra consciência da dificuldade de se compreender fragmentos soltos, descontextualizados, 
distantes dos motivos de sua concepção. Poe decide, então, retornar a certa rigidez formal para garantir entendimento por parte de seu leitor, apesar de, ao mesmo tempo, almejar a uma livre interpretação criativa, à liberdade da imaginação.

Em outro fragmento, publicado em dezembro de 1844, Poe reitera a profunda ligação entre música e poesia dentro de sua estética, ligação igualmente discutida em ensaios como "The Poetic Principle", "The Philosophy of Composition" e aplicada em poemas como "The Raven", "The Bells" e "Annabel Lee":

Sei que a indefinição é elemento da verdadeira música - quero dizer, da verdadeira expressão musical. Atribua-lhe uma decisão indevida - imbua-a com qualquer tom determinado - e você a privará de uma só vez de seu caráter etéreo, ideal, intrínseco e essencial. Você dissipa seu luxo onírico. Você dissolve a atmosfera de misticismo no qual flutua. Você a descarrega de seu sopro de arrebatamento. Torna-se agora uma ideia tangível e fácil - algo da terra, terreno [...]. (Poe, 1984, p. 1331)

Em outro fragmento, publicado em março de 1846 na Graham's Magazine, retoma a importância do material onírico como fundamental para a imaginação criadora, temática que permeia boa parte de seus contos e alguns poemas também. Poe diz como captar os conteúdos provenientes de momentos de sonolência e sonhos e torná-los interessantes e proveitosos para sua estética. Além disso, afirma a impossibilidade de a palavra escrita conseguir captar e transmitir perfeitamente tais conteúdos do 
inconsciente: "Agora, tão íntegra é minha fé no poder das palavras, que por vezes tenho acreditado ser possível incorporar até mesmo a evanescência das fantasias tais como tenho tentado descrevê-las". (Poe, 1984, p. 1384. Grifo original do autor).

Mas é em um longo fragmento publicado na Graham's Magazine em janeiro de 1848 que utiliza a expressão my heart laid bare [meu coração desnudado] para sugerir o título de um livro impossível, segundo ele, de ser escrito. Ao querer notoriedade e tentar revolucionar "o mundo universal do pensamento humano", segundo Poe, qualquer autor que se lançasse em tal projeto estaria fadado a ver literalmente o papel contorcer-se e pegar fogo a cada toque da caneta, ou seja, à destruição de seu texto (Poe, 1984, p. 1423), o que, em última análise, remete ao paradoxo da poética da modernidade: a impossibilidade da palavra e do dizer em contraponto ao dizer da impossibilidade. Como escreve Stirnimann em prefácio para tradução de Conversa sobre Poesia, prefácio esse escrito sob forma de fragmentos, é preciso "compreender a opção pelo fragmento como um artifício tático, forçando uma referência ideal através da incompletude que avisa: o que é mostrado não é o que se quer mostrar." (Stirnimann, 1994, p. 17. Grifo do autor). Ou ainda, segundo Stirnimann,

O fragmento, em sua impostação espirituosa, está sempre a falar de outra coisa, respondendo à intrincada cadeia de tensões que o produz pela lacônica e oblíqua denúncia de um não-manifesto. Escapa do presente insolúvel duplamente: pela mímica do arcaico e por seu caráter sugestivo, antecipatório. Paródia e promessa concentram-se na fórmula que o define - semente de uma resolução futura. 
O trabalho do fragmento consiste, portanto, em duas operações: condensação e deslocamento. Freud devia saber o que dizia quando buscava fragmentos de sonho. (Stirnimann, 1994, p. 18)

O último fragmento que nos interessa aqui, publicado em junho de 1849 na Southern Literary Messenger, sugere um texto autobiográfico. Ao analisar o futuro de um escritor genial, porém isolado e fadado à incompreensão em seu contexto sóciohistórico, Poe parece estar falando de si mesmo. Vale a pena citá-lo integralmente, apesar de sua extensão:

Tenho às vezes me divertido buscando imaginar qual seria o destino de qualquer indivíduo dotado, ou melhor, amaldiçoado, com um intelecto muito superior ao de sua raça. Claro que seria consciente de sua superioridade; nem poderia (a não ser que não fosse constituído como é o homem) deixar de manifestar sua consciência. Assim, faria inimigos em toda parte. E na medida em que suas opiniões e especulações difeririam profundamente das de toda a humanidade, evidentemente seria tachado de louco. Que condição horrivelmente dolorosa! O inferno não poderia inventar maior tortura do que a de ser acusado de fraqueza anormal por ser anormalmente forte.

Do mesmo modo, nada pode ser mais claro do que o fato de que um espírito muito generoso - verdadeiramente sentindo o que os outros meramente dizem sentir - deva ser mal compreendido em todos os sentidos - tendo seus motivos mal interpretados. Assim 
como inteligência extrema seria considerada tolice, assim excesso de cavalheirismo não poderia deixar de ser considerado maldade em último grau - e assim por diante com outras virtudes. Esse tema é de fato doloroso. Que indivíduos tem sofrido acima da média de sua raça é praticamente inquestionável. No entanto, olhando para a história em busca de traços de sua existência, deveremos nos deparar com todas as biografias 'dos bons e dos grandes', enquanto pesquisamos com cuidado os menores registros dos miseráveis que morreram na prisão, no hospício ou no cadafalso. (Poe, 1984, p. 1459 -1460. Grifo do autor). ${ }^{7}$

É importante aqui retomar a relevância do fragmento dentro da estética de Poe. Embora ainda sob o controle da razão, trazendo completude interna, os fragmentos aqui estudados brevemente atestam a preocupação do autor em estabelecer parâmetros estéticos a serem seguidos visando a atingir o público leitor. Entretanto, o próprio Poe demonstra estar ciente da recepção desfavorável por parte da crítica, bem como do escárnio e isolamento a que estaria fadado, como menciona claramente nesse último fragmento. Sabe que suas teorias divergiam do cânone norte-americano, muito mais preocupado com a busca da natureza, de uma poesia orgânica (Beer, 1995), do transcendental religioso, da liberdade subjetiva, do patriotismo exacerbado. Poe, no entanto, prefere o oculto, o negativo, o conflituoso, o difuso da percepção da alma humana. Daí a importância do

7 O termo guignon, ou vítima, em francês, com o qual Baudelaire chamaria Poe em seus ensaios-prefácios a traduções feitas, pode ter origem neste fragmento. 
fragmento nesse autor, principalmente em Marginalia, pois a alma humana é igualmente fragmentária. Portanto, embora não tenha chegado à total dissolução textual, Poe lega fragmentos em Marginalia, principalmente, justapostos sem maiores considerações, saltando de um tema a outro livre, caótica, talvez tão fragmentariamente quanto seu raciocínio. Se a forma, portanto, ainda resiste, está fadada à destruição anunciada em Eureka.

Assim, se Poe compilou quatro volumes com fragmentos de textos, é importante salientar que é Marginalia que fornece material mais significativo para se entender a fragmentação enquanto forma e conteúdo dentro da estética de Poe, tendo sido, assim, mais privilegiado em nossa análise aqui. Nos demais volumes, Fifty Suggestions, A Chapter of Suggestions ou Marginal Notes, além dos fragmentos que brevemente mencionamos aqui, são poucos os trechos que nos fornecem elementos de maior relevância, à exceção de um ou outro tema. No entanto, sua centralidade reside, também, no fato de Baudelaire poder ter-se espelhado neles também enquanto forma para desenvolver Mon Coeur Mis à $\mathrm{Nu}$ [Meu Coração Desnudado], como discute Ruff no prefácio ao livro, em edição das Obras Completas de Baudelaire publicadas pela editora Seuil em 1968:

O título e a concepção desta obra [Mon Coeur Mis à $\mathrm{Nu}$ ] foram emprestados de uma passagem dos Marginalia d'Edgar Poe, tal como assinalado por Jacques Crépet. Poe declara que um livro assim seria de interesse prodigioso se fosse fiel a seu título, mas ninguém jamais ousaria escrevê-lo, nem poderia fazê-lo mesmo se tivesse audácia. O papel não resistiria a essa pluma de fogo. É justamente com um livro assim que sonha 
Baudelaire quando escreve a sua mãe: 'Ah! Se um dia esse livro sair, as Confissões de J.J. [Rousseau] parecerão pálidas'. Suggestions [Sugestões] e Soixante-six suggestions [Sessenta e Seis Sugestões] são igualmente fórmulas emprestadas de Poe, que havia publicado em dois periódicos em 1845 Cinquante Suggestions [Cinquenta Sugestões] e Un Chapitre de suggestions (très bref) [Um Capítulo de Sugestões (muito breve)] ${ }^{8}$. (Baudelaire apud Ruff, 1968, p. 622) ${ }^{9}$

Portanto, se Baudelaire se baseou em Poe para elaborar o projeto de seu último livro (postumamente organizado e publicado por amigos), utilizando não apenas o mesmo título, mas também o mesmo projeto e a mesma forma fragmentária, faz-se necessária uma análise mais detalhada de Mon Coeur Mis à Nu. Uma primeira questão a ser levantada aqui se refere à data de criação dos fragmentos dessa coletânea. Logo após a morte do autor, um pacote de manuscritos inacabados e desorganizados foi entregue a Poulet-Malassis, amigo e editor de Baudelaire, e, posteriormente, a Asselineau, outro amigo. Este o confiou indiretamente a Jacques Crépet, que, em 1887, preparava uma edição definitiva das obras completas do autor francês. A desordem dos originais, aliada à falta de datação precisa e à diversidade de títulos provocou discussão e acarretou, por fim, uma divisão de certo modo aleatória dos escritos. Além disso, Crépet escolheu um novo título, Journaux Intimes [Diários Íntimos], contra a vontade do autor, para quem Mon Coeur Mis à Nu seria o tí-

\footnotetext{
${ }^{8}$ As datas corretas, na realidade, são 1849 e 1845, respectivamente.

9 Todas as citações de Mon Coeur Mis à $N u$ provem da edição das Oeuvres Complètes de Baudelaire publicadas pela Editora Seuil em 1968.
} 
tulo mais apropriado e definitivo, além de se adequar à ideia original de Poe, nunca levada a cabo.

Na edição organizada por Ruff (1968), utilizada aqui, o título sonhado por Baudelaire foi mantido, ao contrário de na edição La Pléiade, considerada definitiva pela crítica, que traz o título Journaux Intimes. A obra consiste em setenta fragmentos de texto sob subtítulos como Fusées, Suggestions, Hygiène, Mon Coeur Mis à Nu, Soixante-six Suggestions, Projets, Conduite, Morale, Méthode [Foguetes, Sugestões, Higiene, Meu Coração Desnudado, Sessenta e Seis Sugestões, Projetos, Conduta, Moral, Método ${ }^{10}$, enfim, uma gama que pode ser explicada devido ao fato de Baudelaire sempre ter tido dificuldades na escolha imediata e eficaz de títulos para suas obras - vide os diversos títulos para Les Fleurs du Mal [Flores do Mal] e Petits Poëmes en Prose [Pequenos Poemas em Prosa].

A grande maioria dos fragmentos encontra-se sob forma incompleta, muitas vezes constituída de frases soltas ou mesmo itens a serem futuramente ampliados, portanto seguindo um esquema menos articulado do que Poe o fez em Marginalia (afinal, o autor norte-americano organizou suas anotações para publicação, ao contrário de Baudelaire). De fato, até o fim da vida, o autor francês viveu a utopia de publicar novos livros, o que pode ser visto no fragmento 30 de Mon Coeur Mis à Nu, escrito sob forma de anotações rápidas ou itens de uma lista a ser ticada à medida em que as tarefas nela anunciadas fossem cumpridas:

História de minha tradução de Edgar Poe.

10 Títulos traduzidos por mim. Não há tradução dessa coletânea para o português. 
História de Fleurs du Mal, humilhação devido a malentendido, e meu processo.

História de meus relacionamentos com todos os homens célebres deste tempo.

Belos retratosde alguns imbecis:

Clément de Ris.

Castagnary.

Retratos de magistrados, funcionários públicos, diretores de jornais, etc.

Retrato do artista em geral [...] (Baudelaire, 1968, p. 633)

E ainda no fragmento 41 do mesmo livro:

Um capítulo sobre a indestrutível, eterna, universal e engenhosa ferocidade humana.

Do amor ao sangue.

Da embriaguez do sangue.

Da embriaguez das multidões.

Da embriaguez do supliciado (Damiens). (Ibid., p. 635)

Também constam anotações à guisa de lembretes: escrever cartas, pagar dívidas, negociar planos, vender futuras publica- 
ções, discutir obras, criticar inimigos literários, saudar escritores semelhantes em ideais, rezar por seu pai, sua babá e Poe ${ }^{11}$.

Passa-se, a seguir, a um levantamento de temas e imagens importantes para se entender a poética e estética de Baudelaire presentes em vários fragmentos de Mon Coeur Mis à Nu.

Logo no primeiro fragmento de Fusées (p. 623) temos temas importantes, como o amor como prostituição ou caridade religiosa e o prazer de estar na multidão (retomando o poema em prosa "Les Foules" [As Multidões] e o conto "The Man in the Crowd" [O Homem da Multidão] de Poe); o fragmento 2 traz a dicotomia entre o uno e o múltiplo, como um turbilhão que envolve o poeta (p. 623). O prazer de fazer o mal, da perversidade inerente ao homem - tema recorrente em poemas em prosa como "Le Mauvais Vitrier" [O Mau Vidraceiro] ou "Assomons les Pauvres" [Espanquemos os Pobres] ou nos contos de Poe como "The Cask of Amontillado" [O Barril de Amontillado], "The Black Cat" [O Gato Preto] ou "Imp of Perverseness" [Ímpeto de Perversidade] - também aparece no fragmento 3: "[...] Eu digo: a volúpia única e suprema do amor gira em torno da certeza de fazer o mal. - E o homem e a mulher sabem de nascença que é no mal que se acha toda a volúpia". (p. 624)

O tema da perversidade é retomado no fragmento 4, que também menciona a importância do sonho como liberação da criatividade, e um plano de escrever um livro sobre sonhos e teoria de sonhos sob influência do místico Swedenborg. (p. 624) Outro fragmento relevante é o 8, por retomar a questão da perversidade e também a viagem, trazendo a imagem do navio como

11 De fato, dois fragmentos lhe servem de lembrete no sentido de rezar pela proteção de Poe, que tê-lo-ia ensinado a pensar. Tal fato revela, mais uma vez, um exagero na idolatria do autor, seu irmão de inspiração, de sofrimento e tédio. 
forma de se chegar ao infinito, tema de poemas de Les Fleurs du Mal e Petits Poëmes en Prose. (p. 625) No fragmento 10 discute a questão do belo e do inesperado, recorrente em vários de seus escritos: "Encontrei a definição do Belo, - de meu Belo. É algo de ardente e de triste, algo um pouco vago, deixando espaço para a conjectura [...]". (p. 626)

Fragmento bastante desenvolvido e, talvez, pronto a ser publicado como ensaio, o 11 discute longamente a "sorcellerie évocatoire" [bruxaria evocatória], função fundamental da imaginação, símbolo de resistência do poeta face à perda de seu lugar na modernidade. (p. 626 - 627) Seria esse fragmento germe do poema em prosa "Perte de l'Auréole" [Perda da Auréola]?

Se fragmentos de Fusées chamam a atenção do leitor por retomar vários aspectos fundamentais dentro da teoria estética de Baudelaire, é em Mon Coeur Mis à $N u$ que o poeta realmente toca o cerne de seu pensamento e produção. O fragmento 16 discute a postulação dual do homem, dividido entre alto e baixo, bem e mal, fragmentação e concretização do eu: "A vaporização e a centralização do Eu. Tudo está lá. [...] Seria talvez doce ser alternativamente vítima e carrasco". (p. 630)

Questões como o horror ao natural através da crítica à mulher e a defesa da figura do dândi, o ressentimento e a desilusão provocados pela Revolução de 1848, a utilidade como algo abominável surgem nos fragmentos 18, 20 e 21, respectivamente. (p. $630-$ 631) Além disso, a incompreensão por parte de seus contemporâneos, da crítica, do público leitor e a sensação inexorável de solidão aparecem no fragmento 22: "Tenho algumas convicções, em um sentido mais elevado, e que não pode ser compreendido pelas pessoas de meu tempo". (p. 631) A dualidade do homem reaparece no fragmento 26, claramente discutida: "Há em todos 
os homens, em todos os momentos, duas postulações simultâneas, uma em direção a Deus, a outra a Satã. A invocação de Deus, ou espiritualidade, é um desejo de progredir; a de Satã é a alegria de descer". (p. 632)

Ou ainda, no fragmento 35: "O que é a queda? Se é a unidade tornada dualidade, foi Deus quem caiu. Em outros termos, a criação não seria a queda de Deus?" (p. 634)

No fragmento 36 , temos a retomada da questão do homem das multidões, dialogando com o fragmento 1 , com o conto de Poe e o poema em prosa baudelairiano "Les Foules" [As Multidões]: " O homem ama tanto o homem que, quando foge da cidade, ainda é para buscar a multidão, ou seja, para refazer a cidade no campo". (p. 634)

O fragmento 45 dialoga com o poema "L'Invitation au Voyage" [Convite à Viagem] e com o poema em prosa "Le Voyage" [A Viagem] com relação ao infinito, à sugestão de infinitude proporcionada pela viagem. (p. 636) O fragmento 53 é fundamental para se entender o tema do culto das imagens, tão importante dentro da estética baudelairiana: "Glorificar o culto das imagens (minha grande, minha única, minha primitiva paixão)". (p. 638)

O tema da queda, bastante recorrente em seus poemas e poemas em prosa, reaparece no fragmento 64, de Fusées:

Tanto moral quanto fisicamente, sempre tive a sensação do abismo, não apenas do abismo do sono, mas do abismo da ação, do sonho, da memória, do desejo, do arrependimento, do remorso, do belo, do número, etc. Tenho cultivado minha histeria com alegria e terror. Agora tenho sempre a vertigem. (p. 640) 
Menciona Poe e De Maistre como mestres no fragmento 65: "De Maistre e Edgar Poe ensinaram-se a raciocinar". (p. 640) É nos fragmentos 66 e 69 de Fusées que Baudelaire consolida o papel do sonho e do poeta na sua estética: "Seja sempre poeta, mesmo na prosa", ou ainda "É preciso querer sonhar e saber sonhar. Evocação da inspiração. Arte mágica”. (p. 641)

Dentre os setenta fragmentos, poucos são os realmente reveladores de sua teoria estética e do diálogo com outros escritos, mas a pequena quantidade é compensada pela profundidade na análise, tais como os fragmentos 10, 11 e 15, que não cabe aqui citar na íntegra, por questão de tempo (p. 626-630). De fato, considerá-los fragmentos pode soar um tanto estranho, na medida em que podem ser vistos como textos bastante desenvolvidos e prontos a serem futuramente publicados. Em todos eles, temos a recorrência e longa retomada de temas caros ao autor: a beleza, o tédio, a morte, a destruição, o desinteresse da burguesia, o enaltecimento político da monarquia, o dandismo, o estranhamento enquanto prazer, o satanismo, a duplicidade entre alto e baixo, as incertezas quanto ao futuro, enfim temas bastante estudados pela crítica. Entretanto, vale ressaltar o caráter fragmentário de grande parte dos fragmentos de cunho estético, justapostos, isolados, descontextualizados e repetitivos: além da repetição no conjunto de fragmentos de alguns temas e imagens, temos também o fato de o autor mencionar reiteradamente nomes e fatos sem maiores detalhes, o que dificulta a compreensão do leitor e torna o texto ainda mais enigmático e entrecortado. Por outro lado, como afirma Stirnimann, na continuação do fragmento anteriormente citado, "A sutileza da manobra exige, no entanto, que o efeito seja amplificado por meio de reiterações insistentes; um fragmento não subsiste sozi- 
nho." (Stirnimann, 1994, p. 17). Reiterar para subsistir, lema que parece comum a Poe e Baudelaire, é preciso salientar.

Apesar de ser em Mon Coeur Mis à $N u$ que Baudelaire levou adiante uma escrita fragmentária, é importante salientar que o movimento de fragmentação na sua obra começou, na realidade, bem antes da publicação desses pequenos textos e notas. Em Petits Poëmes en Prose, a escolha de uma prosa poética já revela a busca da liberação formal como maneira apropriada de se tratar temas como destruição, sátira, mal, queda, tédio, desespero e isolamento, tão constantes nos diversos escritos baudelairianos. Os ensaios analíticos dos salões de arte e das exposições universais revelam, igualmente, certa fragmentação pelo recorte de comentários acerca de elementos e artistas díspares colocados lado a lado no texto. Entretanto, é em Mon Coeur Mis à $N u$ que Baudelaire consegue atingir o objetivo inicial, pensado por Poe, mas abortado rapidamente, de abrir seu coração ao leitor e expor toda sua angústia, insatisfação, revolta e desejo de mudança, sentimentos que percorrem suas obras, mas que, aqui, podem ser mostrados em toda sua totalidade, ou melhor, fragmentação, já que fragmentada é também a alma humana, sua percepção, sua experiência, sua consciência, cercadas por um mundo igualmente fragmentário e fadado à destruição, no entender de Poe e Baudelaire.

Nesse sentido, ambos privilegiam o fragmento enquanto forma capaz de transmitir raciocínio rápido e, muitas vezes, telegráfico, até. Afinal, a livre expressão da alma, a liberdade total de expor sentimentos, ideais, conceitos, só poderia ocorrer com o auxílio de uma forma igualmente livre. O projeto jamais concretizado de Poe no sentido de criar um livro capaz de expressar completa e desimpedidamente tudo o que o artista quisesse - my heart laid 
bare [meu coração desnudado]- e, assim revolucionar o mundo das ideias, dependeria de uma forma capaz de acompanhar a velocidade alucinante de pensamentos caóticos provenientes de nosso inconsciente, forma essa que o fragmento poderia fornecer. De fato, ao tomar para si tal projeto e nos legar escritos nesse sentido, Baudelaire escolhe tal forma e concebe fragmentos, mostrando todos os projetos, sonhos, conceitos estéticos, julgamentos morais que povoavam sua mente criadora e, assim, dialogando com o conjunto de sua obra poética e estética. Entretanto, como já dito anteriormente, a grande maioria de tais fragmentos se apresenta sob a forma de frases ou fragmentos de frase por vezes desconexas e meramente justapostas de forma aleatória. Aliás, o próprio Baudelaire o diz no fragmento 16 de Mon Coeur Mis à Nu: "Posso iniciar Mon Coeur Mis à Nu em qualquer lugar, de qualquer forma, e continua-lo dia a dia, segundo a inspiração do dia e da circunstância, desde que a inspiração esteja viva". (p. 630)

Portanto, os fragmentos baudelairianos aqui mencionados, a nosso ver, dialogam entre si e com os poemas, poemas em prosa e ensaios críticos do seu autor, bem como com os escritos de seu colega norte-americano, estabelecendo, assim certa união dentro da dissolução formal, um conjunto reiterado na fragmentação, no sentido proposto por Stirnimann. O diálogo também parece se ampliar e incluir os fragmentos de Friedrich Schlegel, criando assim uma estética dos fragmentos.

\section{Referências Bibliográficas}

BAUdelaire, C. Oeuvres Complètes. Paris: Seuil, 1968.

- Pequenos Poemas em Prosa. Trad. Dorothée de Bruchard. São Paulo: Hedra, 2007. 
BEER, J.(ed.). Questioning Romanticism. Baltimore: Johns Hopkins University, 1995.

BEIRES, S. "Nathaniel Hawthorne". In: Ensaístas Americanos. Rio de Janeiro: W.M. Jackson, 1950.

BENJAMIN, W. Charles Baudelaire: um lírico no auge do capitalismo. São Paulo: Brasiliense, 1989.

COMPAGNON, A. Le Démon de la Théorie: littérature et sens commun. Paris: Seuil, 1998.

ENGEL, W. Mnemonic Emblems and the Humanist Discourse of Knowledge.

DALY, p. \& MANNING, J. (org). Aspects of Renaissance and Baroque Symbol Theory, 1500-1700. New York: AMS Press, 1998, p. 125-142.

POE, E.A. Essays and Reviews. New York: Library of America, 1984.

. Eureka. New York: Geo. p. Putnam, 1848.

- Obra Poética Completa. Introdução, tradução e notas de Margarida Vale de Gato. Lisboa: Tinta da China, 2009.

SCHEEL, M. Poética do Romantismo: Novalis e o fragmento literário. São Paulo: Ed. , 2010.

VAN SLOOTEN, R. Eureka: Poe's Victory over the Clockwork Universe, 2011.

WATT, I. The Rise of the Novel: studies in Defoe, Richardson and Fielding. NewEdition. London: Vintage Books/Oakland, CA.: University of California Press, 2001. 
